\title{
Optimization of drug therapy in elderly individuals admitted to a geriatric unit
}

\author{
This article was published in the following Dove Press journal: \\ Clinical Interventions in Aging \\ II October 2017 \\ Number of times this article has been viewed
}

\author{
Antoine Piau' \\ Yoann Huet ${ }^{1}$ \\ Adeline Gallini ${ }^{2,3}$ \\ Laurine Andre ${ }^{1-3}$ \\ Bruno Vellas ${ }^{1-3}$ \\ Fati Nourhashemi ${ }^{1-3}$ \\ 'Gérontopôle, Centre Hospitalier \\ Universitaire Toulouse, Toulouse, \\ France; ${ }^{2}$ UMR I 027, INSERM- \\ University of Toulouse, Toulouse, \\ France; ${ }^{3}$ Department of Epidemiology \\ and Public Health, Centre Hospitalier \\ Universitaire Toulouse, Toulouse, \\ France
}

Background: A substantial share of adverse drug events involves inappropriate prescribing (IP). Specialized geriatric units are supposed to pay particular attention to prescribing appropriateness and to promoting a higher prescribing quality.

Objective: The objective of this study was to evaluate the reality of such assessment and optimization in real life (usual care) in a population of elderly individuals admitted to a geriatric unit.

Method: This is an observational study including all older patients admitted to an acute geriatric unit over a 6-month period. As part of usual care, the geriatrician is supposed to detect potentially inappropriate medication and potential prescribing omission using validated tools. The primary outcome was the prevalence rate of therapeutic modifications motivated by treatment optimization (stop, switch, or introduction). Multivariate logistic regression analyses were performed to identify the factors associated with therapeutic discontinuation.

Results: A total of 216 patients were included. The mean age was 85.7 years. Included patients had an average of $7.2 \pm 3.3$ drugs at admission and 5.8 \pm 2.7 at discharge. IP was highly prevalent in our study where about $63 \%$ of the patients had experienced at least one modification because of overuse. The most commonly discontinued medications were drugs used to treat gastroesophageal reflux disease and peptic ulcer disease and serotonin reuptake inhibitor antidepressants. The most commonly introduced medications were analgesics and warfarin. By using multivariate analysis, we found that patient age and number of drugs on admission were significantly associated with medication discontinuation during hospital stay.

Conclusion: In this real-life study of all patients admitted to a Geriatric Post Emergency Unit, $83 \%$ of the patients had a treatment modification during hospital stay. The most original result of our study is the clear reduction in polypharmacy during hospitalization.

Keywords: elderly, inappropriate prescriptions, geriatric unit, overuse, misuse, underuse

\section{Introduction}

Polypharmacy and adverse drug reactions (ADRs) increase with advancing age, as well as ADR-related hospitalization and life-threatening ADRs. ${ }^{1,2}$ Most cases involve inappropriate monitoring of a few well-known commonly used drugs ${ }^{1,2}$ but a substantial part of avoidable adverse drug events involves inappropriate prescribing (IP). ${ }^{3,4}$ IP is highly prevalent in the geriatric population. ${ }^{5-7}$ IP encompasses potentially inappropriate medications (PIMs), so-called overuse and/or misuse; and potential prescribing omissions (PPOs), so-called underuse..$^{8-10}$

Over the last years, several screening tools have been increasingly used to identify potential IP in older adults. The most frequently used are the Beers criteria, ${ }^{11}$ the Screening Tool of Older Person's Prescriptions (STOPP), ${ }^{12}$ and the Screening Tool to Alert doctors to Right Treatment (START) criteria. ${ }^{12,13}$
Cité de la Santé, 20-24 rue du Pont Saint-Pierre, 31052 Toulouse, France Tel +33561323010

$\mathrm{Fax}+33561323396$

Email piau.a@chu-toulouse BY NC and incorporate the Creative Commons Attribution - Non Commercial (unported, v3.0) License (http://creativecommons.org/licenses/by-nd / $3.0 /$ ). By accessing the work you
hereby accept the Terms. Non-commercial uses of the work are permitted without any further permission from Dove Medical Press Limited, provided the work is properly attributed. For permission 
Many older people are admitted to the hospital because of an acute disease. This acute event takes place in a context of chronic diseases as well as cognitive impairment and/or functional decline, which complicates treatment during hospital stays and after discharge. ${ }^{14}$ In specialized geriatric units, the comprehensive geriatric assessment approach is effective at addressing this challenge and preventing adverse events during and after the hospital stays. ${ }^{14}$ Specialized geriatric units are also supposed to pay particular attention to prescribing appropriateness and to promoting a higher prescribing quality: ${ }^{10}$ stopping unnecessary or harmful medications (overuse), switching from an inappropriate medication to a better one (misuse), or introducing an omitting treatment (underuse). STOPP and START criteria may be effective in improving prescribing quality and clinical and economic outcomes $^{12}$ but according to a recent Cochrane review, it remains unclear whether interventions to improve appropriate use of polypharmacy result in clinically significant improvements. ${ }^{15}$

The objective of this study was to evaluate the reality of such drug therapy assessment and optimization in real life (usual care) in a population of elderly individuals admitted to a geriatric unit. Specifically, we aimed to estimate the prevalence of treatment modifications, reasons for modifications, and the factors associated with such modifications and especially drug discontinuations.

\section{Method}

\section{Design}

This is an observational study including all older patients admitted to an acute geriatric unit over a 6-month period.

\section{Setting}

It is a 12-bed Geriatric Unit in Toulouse University teaching hospital. All patients hospitalized in this unit are admitted via the emergency department and are under the care of geriatricians.

\section{Population}

From the 1st of November 2012 to the 30th of April 2013, all patients aged $\geq 65$ years consecutively admitted to the unit were screened for enrolment in the study. Patients were not included if they 1) were suffering from a terminal disease requiring intensive palliative care, 2) died while staying in the unit, 3) were transferred to another hospital acute care ward, or 4) had already been hospitalized in the unit during the preceding year.

\section{Procedures}

As part of usual care, the geriatrician is supposed to detect PIM and PPO, using validated criteria.

\section{Data collection}

Within 24 hours of each patient's hospitalization, the geriatrician, as part of routine care, conducted a patient and/or caregiver and general practitioner interview and chart review to collect the following data: sociodemographic details, current medications with the Anatomical Therapeutic Chemical classification (http://www.whocc.no/atc/structure and principles/), chronic diseases, and cognitive abilities. Main reason for admission, drug prescriptions on discharge, and reasons underlying treatment modifications during hospital stay were also specified in the hospitalization chart as part of routine care. All these data were compiled for analysis. PIM was defined as the presence of the drug on one of the following lists: STOPP and START criteria, ${ }^{16}$ and BEERS criteria. Medication introduction was defined as the introduction of an omitted drug according to the START criteria. Therefore, short-duration drug regimens for acute diseases (eg, antibiotics) were not taken into account. Medication stop was defined as the interruption of a drug considered as inappropriate in this particular situation (overuse and misuse) according to BEERS and/or STOPP criteria. Medication switch was defined as the replacement of an inappropriate drug (misuse) by another one.

The institutional ethical board of the Toulouse University Hospital deemed this observational study exempt from review under current regulations. Informed consent was not required as patient's data were processed in complete confidentiality, according to high-quality medical practices.

\section{Statistical analysis}

We performed descriptive statistics to illustrate the characteristics of the study population. The primary outcome was the prevalence rate of therapeutic modifications (stop, switch, or introduction) with $95 \%$ bilateral CI. Multivariate logistic regression analyses were performed to identify the factors associated with therapeutic discontinuation.

$P$-values $<0.05$ were considered statistically significant. All the analyses were performed with STATA 11.2 software (College Station, TX: StataCorp LP).

\section{Results}

\section{Population characteristics}

A total of 216 patients were included out of 309 patients who had been discharged from the unit during the study period. 
It did represent 322 hospitalizations as several patients were hospitalized more than once during the study period. A total of 92 patients (106 hospitalizations) were excluded: 45 patients were in terminal palliative care, 18 patients were transferred to another acute hospital ward, 12 were unable to be analyzed because of an incomplete medical file, 17 died, and 14 had already been hospitalized in the unit in the last year.

Among the 216 included patients, 134 (62.0\%) were women and $82(38.0 \%)$ were men. The mean age was $85.7 \pm 6.4$ years, and $74.9 \%$ were living in the community. The main reasons for hospitalization were dyspnea $(n=104$, $48.1 \%)$. Twenty-nine (13.4\%) patients suffered from one to three chronic diseases; 133 (61.6\%) from four to six chronic diseases; and 54 (25.0\%) from seven or more chronic diseases (Table 1). Included patients had an average of 7.2 \pm 3.3 drugs on admission.

\section{Drug prescriptions}

The number of drugs and the number or treatment modifications on admission are described in Table 2 . Included patients had an average of $7.2 \pm 3.3$ drugs (min 0 , max 15) on admission and $5.8 \pm 2.7$ (min 0 ; $\max 15)$ on discharge.

There were 543 changes to prescribed medications during the study period. Three hundred seventy-nine medications were stopped and only 64 (16.9\%) of them were replaced, 99 medications were introduced during the hospital stay, 93 of them because of an underuse situation. One hundred

Table I Characteristics of the population $(n=2 \mid 6)$

\begin{tabular}{ll}
\hline Characteristics & N (\%) \\
\hline Sex & $134(62.0)$ \\
Women & $82(38.0)$ \\
Men & \\
Age (years) & $83(38.4)$ \\
$65-84$ & $133(61.6)$ \\
$85-90+$ & \\
Main hospitalization cause & $104(48.1)$ \\
Dyspnea & $47(21.8)$ \\
Falls & $45(20.8)$ \\
Autonomy loss or social concern & $36(16.7)$ \\
Delirium & \\
Type of residence & $161(74.9)$ \\
Community dwelling & $54(25.1)$ \\
Nursing homes & $87(40.5)$ \\
Patients suffering from cognitive disorders & \\
Number of comorbidities per patient & $29(13.4)$ \\
I-3 & $133(61.6)$ \\
$4-6$ & $54(25.0)$ \\
\hline $7+$ &
\end{tabular}

Abbreviation: $\mathrm{N}$, number.
Table 2 Treatment characteristics on admission and discharge and modifications during hospitalization $(\mathrm{N}=216)$

\begin{tabular}{ll}
\hline Characteristics & Value \\
\hline Medication per patient, $\mathbf{N}(\%)$ & \\
5 or less & $72(33.3)$ \\
$6-9$ & $92(42.6)$ \\
I0+ & $52(24.1)$ \\
Drugs on admission, mean \pm SD & $7.2 \pm 3.3$ \\
Drugs on discharge, mean \pm SD & $5.8 \pm 2.7$ \\
Number of treatment modifications per patient, $\mathbf{N}(\%)$ \\
I & 5 I $(23.6)$ \\
$2-5$ & $108(50.0)$ \\
$6+$ & $21(9.7)$ \\
Changes per patient, N (\%) & \\
$\geq$ I stop & $158(73.1)$ \\
$\geq$ I introduction & $64(29.6)$ \\
$\geq$ I switch & $53(24.5)$ \\
\hline
\end{tabular}

Abbreviations: N, number; SD, standard deviation.

eighty patients had at least one modification to their treatment (83.3\%, 95\% CI =[78.3-88.3]). Among those who had at least one modification to their treatment, $51(28.3 \%)$ had one modification, $108(60.0 \%)$ between two and five modifications, and $21(11.7 \%)$ six modifications or more. The prevalence of drug changes is presented in Table 2.

IP was highly prevalent in our study where about $63 \%$ of the patients had experienced at least one modification because of overuse. Prevalence of IP is presented in Table 3.

The most commonly discontinued medications were drugs used to treat gastroesophageal reflux disease and peptic ulcer disease (A02B, 16.9\%), of which 1.5\% were replaced, but also:

- Serotonin reuptake inhibitor (SRI) antidepressants (N06A, 11.3\%),

- Vasodilators (C01D, 9.0\%),

- Class I and III antiarrhythmic specifically amiodarone and flecainide (C01B, 4.5\%),

- Cholesterol-lowering drugs (C10A, 3.7\%), mainly statins,

- Medications used for treatment of benign prostatic hyperplasia (G04C, 3.7\%) (Table 4).

The most commonly introduced medications in our study were:

- Analgesics and antipyretics (N02B, 26.3\%),

Table 3 Prevalence of inappropriate prescription $(\mathrm{N}=216)$

\begin{tabular}{lll}
\hline & Patients (n) & $\%$ \\
\hline$\geq I$ overuse & 137 & 63.4 \\
$\geq I$ underuse & 63 & 29.2 \\
$\geq I$ misuse & 91 & 42.1 \\
\hline
\end{tabular}

Abbreviation: $\mathrm{N}$, number. 
Table 4 Most commonly discontinued medications

\begin{tabular}{lll}
\hline Drugs (ATC code) & $\begin{array}{l}\text { Discontinued } \\
\text { medications (\%) }\end{array}$ & $\begin{array}{l}\text { Replacement } \\
\text { medications (\%) }\end{array}$ \\
\hline Gastroesophageal reflux disease and peptic ulcer disease drugs (A02B) & 16.9 & 1.5 \\
Serotonin reuptake inhibitor antidepressants (N06A) & 11.3 & 1.5 \\
Vasodilators (C0ID) & 9.0 & 0.0 \\
Class I and III antiarrhythmics (C0IB) & 4.5 & 1.5 \\
Cholesterol-lowering drugs (CIOA) & 3.7 & 1.5 \\
Benign prostatic hyperplasia drugs (G04C) & 3.7 & 0.0 \\
Anxiolytics and hypnotics (N05B-C) & 3.7 & 26.1 \\
Antipsychotic drugs (N05A) & 3.2 & 3.08 \\
\hline
\end{tabular}

Abbreviation: ATC, Anatomic, Therapeutic, and Chemical Classification.

- Warfarin (B01AA03, 7.1\%) and acetylsalicylic acid (B01AC06, 6.1\%),

- Laxatives (A06A, 9.1\%),

- Calcium with vitamin D (A12A, 8.1\%),

- Vitamin B 12 and folic acid (B03B, 7.1\%),

- Anxiolytics (N05B, 6.1\%).

One hundred thirty-two subjects had at least one drug discontinuation during hospital stay and the prevalence was $61.11 \%(95 \% \mathrm{CI}=[54.61-67.61])$. By using multivariate analysis, we found that patient age and the number of drugs on admission were significantly associated with medication discontinuation during the hospital stay (Table 5).

\section{Discussion}

The most original results of our study are the clear reduction of polypharmacy during hospitalization (ie, average decrease of 1.4 drugs per patient), despite the fact that 93 medications were introduced during the hospital stay because of an underuse situation (PPO). Even if drug regimen optimization does not necessarily lead to a reduction in the total number of drugs, this shows that it is possible to limit polymedication while taking into account underuse. The study of Frély et al ${ }^{7}$ showed, in the same context, that hospitalization in an acute

Table 5 Factors associated with medication discontinuation in multivariate analysis $(n=2 \mid 4)$

\begin{tabular}{llll}
\hline & OR & $\mathbf{9 5 \%} \mathbf{C l}$ & $P$-value \\
\hline Age (years) & & & \\
Under 85 & $\mathrm{I}$ & & 0.021 \\
$85+$ & 2.04 & $\mathrm{I} . \mathrm{II}-3.75$ & \\
Male (vs female) & 0.84 & $0.46-1.55$ & 0.585 \\
Living in institution (vs community) & $\mathrm{I} .40$ & $0.69-2.87$ & 0.356 \\
Number of drugs on admission & & & \\
5 or less & $\mathrm{I}$ & & 0.018 \\
$6-9$ & 2.53 & $1.29-4.94$ & \\
I0+ & 2.16 & $0.99-4.68$ & \\
Hospital admission for fall & 1.97 & $0.93-4.14$ & 0.075 \\
\hline
\end{tabular}

Abbreviations: $\mathrm{OR}$, odds ratio; $\mathrm{Cl}$, confidence interval. geriatric unit leads to a statistically significant decrease in the number of PIMs on discharge but without any reduction of polypharmacy (there was an increase in the total number of drugs) and PPOs. These results are close to those found in another study conducted in a comparable setting. ${ }^{21}$ Verrue et al and Legrain et al also observed that evaluation of prescriptions by a geriatrician led to several qualitative changes but without, in most cases, a reduction in the number of drugs prescribed..$^{22,23}$ Elsewhere, Tulner et al reported, in an outpatient context, that a consultation during which geriatric assessment was carried out led to a reduction in underuse. ${ }^{24}$ Two other studies evaluating interventions to improve underuse reported a greater reduction of PPOs in the intervention group compared with the control group,,$^{25,26}$ but these studies did not assess "real life" optimization in a geriatric unit.

In the current study, the mean number of prescription (7.2 drugs) was consistent with the literature. The number of drug regimen modifications during hospitalization (ie, 543 changes in prescribed medications during the study $-83.3 \%$ of patients had at least one modification to their treatment), with a large majority of drug interruptions ( 379 medications were discontinued), were in line with the high prevalence of PIMs. These results are consistent with those previously reported in the literature. ${ }^{7,17,18,21}$ The most commonly discontinued medications in our sample study were drugs used to treat gastroesophageal reflux disease and peptic ulcer disease (A02B) because of an overuse of proton pump inhibitors, which is also consistent with the literature. ${ }^{7,19,21}$ We also found an overuse of SRI antidepressants (N06A), which appear to be too rarely re-evaluated with a systematic prescription renewal for years despite their risks for older people. ${ }^{20}$ In a comparable French geriatric hospitalization context, Frély et $\mathrm{al}^{7}$ and Andro et $\mathrm{al}^{21}$ found more benzodiazepines and antipsychotic medications overuse in their study panel. This could be explained by the awareness-raising efforts made these last years in this domain. Among the most 
commonly discontinued medications, vasodilators were well represented, which is consistent with the literature. ${ }^{7,21}$ Antiarrhythmic medications were also often overused. The most frequent situations were the prescription of flecainide or amiodarone without indication.

In the present study we found high prevalence of PPOs. The most commonly introduced medications were analgesics and antipyretics (N02B), warfarin (B01AA03) and acetylsalicylic acid (B01AC06), laxatives (A06A), and calcium with vitamin D (A12A). Apart from laxatives, this is highly consistent with the main situation of underuse found in the study by Andro et al. ${ }^{21}$ Frély et al $^{7}$ also found a great number of prescribed opiates without associated laxatives and calcium with vitamin D supplements. Underuse of oral anticoagulants is a well-known concern in our older population. ${ }^{27}$ These cases could be mainly explained by an unjustified supposed contraindication in increased risk of fall situations. ${ }^{28}$

We found that, in the multivariate analysis, two factors were significantly associated with medication discontinuations during hospital stay: age and the number of drugs on admission. Frély et $\mathrm{al}^{7}$ and Andro et $\mathrm{al}^{21}$ also found such an association between the number of drugs and PIM. The association of the number of drugs and adverse drugs effects is well described elsewhere. ${ }^{5}$ In a community-dwelling population, Lechevallier-Michel et al also found a significant association between age and inappropriate medications. ${ }^{6}$

Our study presents several major limitations. First, the diversity of tools used to evaluate and optimize treatment and the debates over the definition of overuse, misuse, and underuse is a shared limit to this kind of study. Second, one particular limit to our work is the evaluation of treatment modifications during hospital stay by a single evaluator. Third, the assessment of the appropriateness of the drug is based on the information available from the medical data provided by the hospitalization medical record, which could lead to incomplete information and consequently the numbers of PPI may be overestimated. Finally, our population panel could not be representative of the overall aged population. The unit belongs to a university teaching hospital with a recruitment of patients presenting multiple and complex medical disorders.

\section{Conclusion}

The main objective of this real-life study was to evaluate the reality of drug therapy assessment and optimization in patients admitted to a Geriatric Post Emergency Unit over a 6 -month period. We found that $83 \%$ of the patients had a treatment modification during their hospital stay and a clear reduction of polypharmacy. This high prevalence of treatment modification seems to be in line with a higher prescribing quality (eg, stopping harmful medications and/or introducing an omitting treatment) according to validated tools. Our study confirms that such acute geriatric unit promotes a higher prescribing quality. This goal is achievable, thanks to simple and convenient tool, and could potentially be used in all nonspecialized units.

\section{Disclosure}

The authors report no conflicts of interest in this work.

\section{References}

1. Pedrós C, Formiga F, Corbella X, Arnau JM. Adverse drug reactions leading to urgent hospital admission in an elderly population: prevalence and main features. Eur J Clin Pharmacol. 2016;72(2):219-226.

2. Franceschi M, Scarcelli C, Niro V, et al. Prevalence, clinical features and avoidability of adverse drug reactions as cause of admission to a geriatric unit: a prospective study of 1756 patients. Drug Saf. 2008; 31(6):545-556.

3. Dalleur O, Spinewine A, Henrard S, Losseau C, Speybroeck N, Boland B. Inappropriate prescribing and related hospital admissions in frail older persons according to the STOPP and START criteria. Drugs Aging. 2012;29(10):829-837.

4. van der Stelt CA, Vermeulen Windsant-van den Tweel AM, Egberts AC, et al. The association between potentially inappropriate prescribing and medication-related hospital admissions in older patients: a nested case control study. Drug Saf. 2016;39(1):79-87.

5. Passarelli MCG, Jacob-Filho W, Figueras A. Adverse drug reactions in an elderly hospitalised population: inappropriate prescription is a leading cause. Drugs Aging. 2005;22(9):767-777.

6. Lechevallier-Michel N, Gautier-Bertrand M, Alpérovitch A, et al. Frequency and risk factors of potentially inappropriate medication use in a community-dwelling elderly population: results from the 3C Study. Eur J Clin Pharmacol. 2005;60(11):813-819.

7. Frély A, Chazard E, Pansu A, Beuscart JB, Puisieux F. Impact of acute geriatric care in elderly patients according to the screening tool of older persons' prescriptions/screening tool to alert doctors to right treatment criteria in northern France. Geriatr Gerontol Int. 2016;16(2): 272-278.

8. Onder G, van der Cammen TJ, Petrovic M, Somers A, Rajkumar C. Strategies to reduce the risk of iatrogenic illness in complex older adults. Age Ageing. 2013;42(2):284-291.

9. O'Connor MN, Gallagher P, O'Mahony D. Inappropriate prescribing: criteria, detection and prevention. Drugs Aging. 2012;29(6):437-452.

10. Hanlon JT, Schmader KE, Ruby CM, Weinberger M. Suboptimal prescribing in older inpatients and outpatients. J Am Geriatr Soc. 2001; 49(2):200-209.

11. American Geriatrics Society 2015 Beers Criteria Update Expert Panel. American Geriatrics Society 2015 updated beers criteria for potentially inappropriate medication use in older adults. $J$ Am Geriatr Soc. 2015;63(11):2227-2246.

12. Hill-Taylor B, Walsh KA, Stewart S, Hayden J, Byrne S, Sketris IS. Effectiveness of the STOPP/START criteria: systematic review and meta-analysis of randomized controlled studies. J Clin Pharm Ther. 2016;41(2):158-169.

13. Gallagher P, Ryan C, Byrne S, Kennedy J, O’Mahony D. STOPP (Screening Tool of Older Person's Prescriptions) and START (Screening Tool to Alert doctors to Right Treatment). Consensus validation. Int J Clin Pharmacol Ther. 2008;46(2):72-83.

14. Van CK, Braes T, Wellens N, et al. The effectiveness of inpatient geriatric evaluation and management units: a systematic review and meta-analysis. J Am Geriatr Soc. 2010;58(1):83-92. 
15. Cooper JA, Cadogan CA, Patterson SM, et al. Interventions to improve the appropriate use of polypharmacy in older people: a cochrane systematic review. BMJ Open. 2015;5(12):e009235.

16. Lang PO, Hasso Y, Belmin J, et al. [STOPP-START: adaptation of a French language screening tool for detecting inappropriate prescriptions in older people]. Can J Public Health. 2009;100(6):426-431. French.

17. Gallagher P, Lang PO, Cherubini A, et al. Prevalence of potentially inappropriate prescribing in an acutely ill population of older patients admitted to six European hospitals. Eur J Clin Pharmacol. 2011;67(11): $1175-1188$.

18. Corsonello A, Onder G, Abbatecola AM, Guffanti EE, Gareri P, Lattanzio F. Explicit criteria for potentially inappropriate medications to reduce the risk of adverse drug reactions in elderly people: from Beers to STOPP/START criteria. Drug Saf. 2012;35(Suppl 1):21-28.

19. Delcher A, Hily S, Boureau AS, Chapelet G, Berrut G, de Decker L. Multimorbidities and overprescription of proton pump inhibitors in older patients. PLoS One. 2015;10(11):e0141779.

20. Coupland C, Dhiman P, Morriss R, Arthur A, Barton G, Hippisley-Cox J. Antidepressant use and risk of adverse outcomes in older people: population based cohort study. BMJ. 2011;343:d4551.

21. Andro M, Estivin S, Gentric A. Medicinal prescriptions in geriatrics: overuse, misuse, underuse. Qualitative analysis from the prescriptions of 200 patients admitted in an acute care geriatric unit. Rev Med Interne. 2012;33(3):122-127.

22. Legrain S, Tubach F, Bonnet-Zamponi D, et al. A new multimodal geriatric discharge-planning intervention to prevent emergency visits and rehospitalizations of older adults: the optimization of medication in AGEd multicenter randomized controlled trial. J Am Geriatr Soc. 2011;59(11):2017-2028.
23. Verrue CL, Petrovic M, Mehuys E, Remon JP, Vander Stichele R. Pharmacists' interventions for optimization of medication use in nursing homes: a systematic review. Drugs Aging. 2009;26(1):37-49.

24. Tulner LR, van Campen JPCM, Frankfort SV, et al. Changes in undertreatment after comprehensive geriatric assessment: an observational study. Drugs Aging. 2010;27(10):831-843.

25. Gallagher P, O’Connor M, O’Mahony D. Prevention of potentially inappropriate prescribing for elderly patients: a randomized controlled trial using STOPP/START criteria. Clin Pharmacol Ther. 2011;89(6): 845-854.

26. Schmader KE, Hanlon JT, Pieper CF, et al. Effects of geriatric evaluation and management on adverse drug reactions and suboptimal prescribing in the frail elderly. Am J Med. 2004;116(6):394-401.

27. Bahri O, Roca F, Lechani T, et al. Underuse of oral anticoagulation for individuals with atrial fibrillation in a nursing home setting in France: comparisons of resident characteristics and physician attitude. $\mathrm{J} \mathrm{Am}$ Geriatr Soc. 2015;63(1):71-76.

28. Man-Son-Hing M, Nichol G, Lau A, Laupacis A. Choosing antithrombotic therapy for elderly patients with atrial fibrillation who are at risk for falls. Arch Intern Med. 1999;159(7):677-685.
Clinical Interventions in Aging

\section{Publish your work in this journal}

Clinical Interventions in Aging is an international, peer-reviewed journal focusing on evidence-based reports on the value or lack thereof of treatments intended to prevent or delay the onset of maladaptive correlates of aging in human beings. This journal is indexed on PubMed Central, MedLine,

\section{Dovepress}

CAS, Scopus and the Elsevier Bibliographic databases. The manuscript management system is completely online and includes a very quick and fair peer-review system, which is all easy to use. Visit http://www.dovepress. com/testimonials.php to read real quotes from published authors. 